\title{
Incorporation of a metal-mediated base pair into an ATP aptamer - using silver(I) ions to modulate aptamer function
}

\author{
Marius H. Heddinga and Jens Müller
}

\section{Full Research Paper}

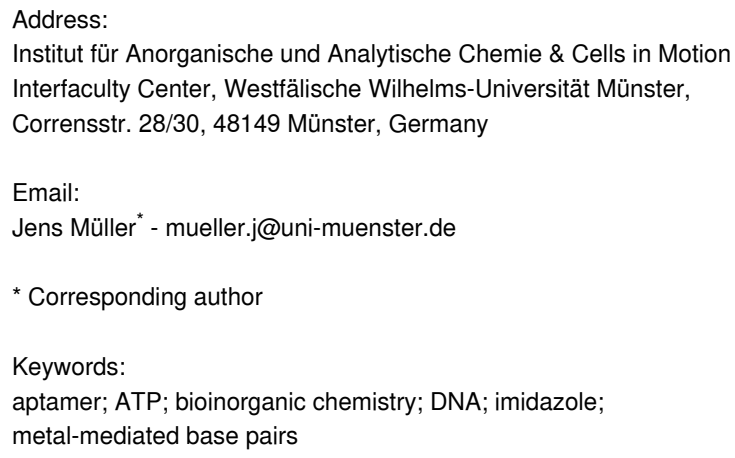

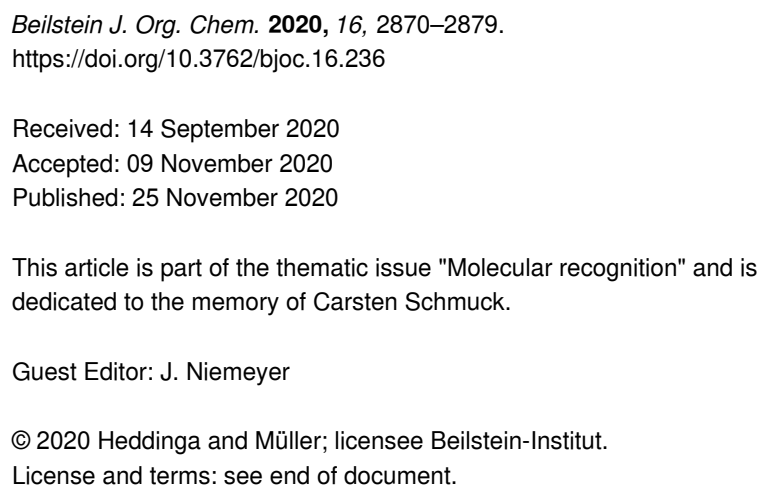

\begin{abstract}
For the first time, a metal-mediated base pair has been used to modulate the affinity of an aptamer towards its target. In particular, two artificial imidazole 2'-deoxyribonucleosides ( $\mathrm{Im}$ ) were incorporated into various positions of an established ATP-binding aptamer (ATP, adenosine triphosphate), resulting in the formation of three aptamer derivatives bearing Im:Im mispairs with a reduced ATP affinity. A fluorescence spectroscopy assay and a binding assay with immobilized ATP were used to evaluate the aptamer derivatives. Upon the addition of one $\mathrm{Ag}(\mathrm{I})$ ion per mispair, stabilizing $\mathrm{Im}-\mathrm{Ag}(\mathrm{I})-\mathrm{Im}$ base pairs were formed. As a result, the affinity of the aptamer derivative towards ATP is restored again. The silver(I)-mediated base-pair formation was particularly suitable to modulate the aptamer function when the Im:Im mispairs (and hence the resulting metal-mediated base pairs) were located close to the ATP-binding pocket of the aptamer. Being able to trigger the aptamer function opens new possibilities for applications of oligonucleotides.
\end{abstract}

\section{Introduction}

Aptamers are oligonucleotides capable of recognizing and binding to specific molecules up to the size of proteins [1]. While mostly unstructured in solution, aptamers typically fold into their three-dimensional structure upon binding the respective target molecule [2]. Aptamers are normally identified by the in vitro selection from combinatorial libraries of nucleic acids [3]. In the past decades, interest in aptamers has risen sig- nificantly, as they can be applied in a variety of disciplines, e.g., as therapeutics or as sensors [4-7].

Another topical area of research in the field of nucleic acids involves the development of nucleic acids whose structure (and therefore function) can be regulated by the addition (or removal) of external triggers, allowing to switch the nucleic 
acid function [8]. For example, DNA can be used in nanotechnology to create mechanically moving systems such as walkers, fueled by the addition of appropriately designed oligonucleotides [9]. Moreover, external triggers can be applied to release a DNA-bound cargo (in the form of small organic molecules) [10]. Similarly, metal ions can trigger DNA folding into a catalytically active topology $[11,12]$.

Metal-mediated base pairs are artificial base pairs in which hydrogen bonds between the complementary nucleobases are formally replaced by coordinate bonds to one (or more) transition metal ions $[13,14]$. They are compatible with normal DNA duplex structures $[15,16]$ and can be used to introduce a metalbased functionality into DNA $[17,18]$. Importantly, metal-mediated base-pair formation has been successfully applied in metalresponsive structural transformations of various types [19-21] We therefore envisaged the development of an aptamer whose function would be modulated by the formation of a metal-mediated base pair. So far, only one example exists of such a rationally designed aptamer. In that work, a thrombin-binding aptamer that adopts a guanine quadruplex structure was modified by four pyridine ligands [22]. The addition of $\mathrm{Cu}$ (II) or $\mathrm{Ni}$ (II) ions leads to the formation of a square-planar complex that reduces the affinity of the modified aptamer to its target protein. To the best of our knowledge, there is no precedence for an aptamer whose affinity is restored upon metal-mediated base-pair formation. One example exists of a $\mathrm{Ag}(\mathrm{I})$-binding aptamer, but that aptamer does not rely on the formation of a $\operatorname{Ag}(\mathrm{I})$-mediated base pair $[23,24]$.

The aptamer selected for this study is the ATP-binding aptamer (ATP, adenosine triphosphate) [25]. The choice of this aptamer was expected to have various advantages. 1) Its three-dimensional structure has been reported [26], so the position for the incorporation of the metal-mediated base pair can be chosen in a meaningful way. 2) Its structure is based on a duplex rather than a quadruplex, so that metal-mediated base pairs can be introduced. 3) It is a short oligonucleotide, so the modified aptamers can easily be synthesized using automated solid-phase synthesis. 4) The target molecule of this aptamer is a small molecule, facilitating the binding assays. 5) The aptamer also binds AMP (adenosine monophosphate) with high affinity [25], which is less prone to hydrolysis than ATP and can therefore comfortably be used in the binding assays. 6) Finally, the ATP aptamer has already been exploited in many other contexts such as in DNA origami [27-29], indicating its high versatility.

The metal-mediated base pair chosen for this study is based on the artificial imidazole 2'-deoxyribonucleoside (Im). This nucleoside is well known to form highly stabilizing $\mathrm{Ag}(\mathrm{I})$-mediated $\mathrm{Im}-\mathrm{Ag}(\mathrm{I})-\mathrm{Im}$ base pairs (Figure 1) [30-33] and has already been proposed for a use in various applications [34-36]. A slight disadvantage of using this metal-mediated base pair could be the fact that $\mathrm{Ag}(\mathrm{I})$ is known to have an affinity to adenine derivatives (such as ATP, i.e., the target molecule of the aptamer) $[37,38]$. However, as the incorporation into an $\mathrm{Im}-\mathrm{Ag}(\mathrm{I})-\mathrm{Im}$ base pair should be favoured by the chelate effect, compared to the binding to ATP, the combination of ATP-binding aptamer and $\mathrm{Im}-\mathrm{Ag}(\mathrm{I})-\mathrm{Im}$ base pair was finally selected for this study.



Figure 1: Chemical structure of the $\mathrm{Im}-\mathrm{Ag}(\mathrm{I})-\mathrm{Im}$ base pair [30].

\section{Results and Discussion}

Four ATP/AMP aptamer derivatives were synthesized and terminally labeled with a fluorescein moiety. Three of these have Im:Im pairs inserted at different positions into the sequence (Figure 2). The oligonucleotide 1af is essentially iden-



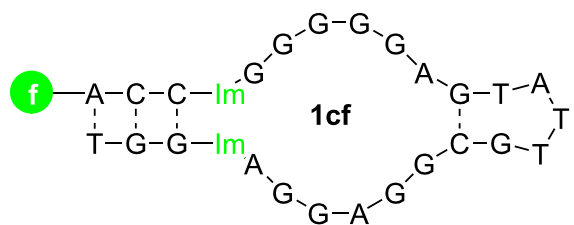

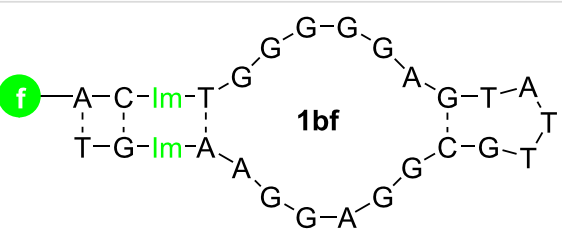

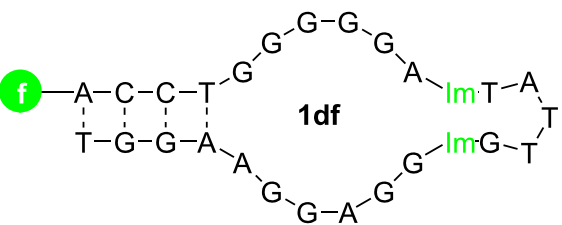

Figure 2: The aptamer derivatives used in this study. The imidazole deoxyribonucleotide is marked in green as Im, while f represents fluorescein 
tical to the established ATP/AMP-binding aptamer, with the attached fluorescein moiety representing the sole difference. The oligonucleotide 1 bf bears one Im:Im pair located two base pairs away from the 5' and 3' ends of the aptamer. The aptamer derivatives $1 \mathbf{c f}$ and $1 \mathbf{d f}$ contain one $\mathrm{Im}: \mathrm{Im}$ pair directly adjacent to the central binding pocket. For 1cf, the Im:Im pair is located towards the termini, whereas in derivative 1df it is close to the loop region.

\section{Melting curves and CD spectroscopy}

To evaluate whether the $\operatorname{Ag}(\mathrm{I})$-mediated base pairs are indeed formed in the aptamer derivatives, melting curves and circular dichroism (CD) spectra were recorded in the presence of increasing amounts of $\operatorname{Ag}(\mathrm{I})$. The DNA melting is expected to occur when the loop structure of the aptamers opens up.

In the absence of $\operatorname{Ag}(\mathrm{I})$, aptamer 1af shows the highest melting temperature $T_{\mathrm{m}}$ of all aptamer derivatives $\left(44{ }^{\circ} \mathrm{C}\right.$, Figure 3$)$. In contrast, the modified aptamers melt at a significantly lower temperature $\left(31^{\circ} \mathrm{C}\right)$. As these derivatives bear the $\mathrm{Im}$ :Im pair directly adjacent to the ATP binding pocket, it can be concluded that the nucleobases close to the binding pocket contribute to a large extent to the aptamer stability. All imidazole-containing aptamer derivatives (1bf, 1cf, 1df) show a significant increase in $T_{\mathrm{m}}$ upon the addition of the first equivalent of $\mathrm{Ag}(\mathrm{I})$ but only minor additional changes in the presence of excess $\operatorname{Ag}(\mathrm{I})$. This is a typical indication for the formation of a $\operatorname{Ag}(\mathrm{I})-$ mediated base pair [17]. It is therefore likely that the increased stability is caused primarily by the formation of one Im-Ag(I)-Im base pair. In contrast, the aptamer 1af lacking any imidazole residues shows a much smaller increase in $T_{\mathrm{m}}$. Moreover, the $T_{\mathrm{m}}$ of $1 \mathrm{af}$ increases more or less steadily with an increasing $\operatorname{Ag}(\mathrm{I})$ concentration, suggesting non-specific interactions between $\operatorname{Ag}(\mathrm{I})$ and the canonical nucleobases in 1af.

To obtain further insight into the $\mathrm{Ag}(\mathrm{I})$-binding behavior of the aptamer derivatives, CD spectra were recorded (Figure S1 in Supporting Information File 1). All aptamer derivatives show a
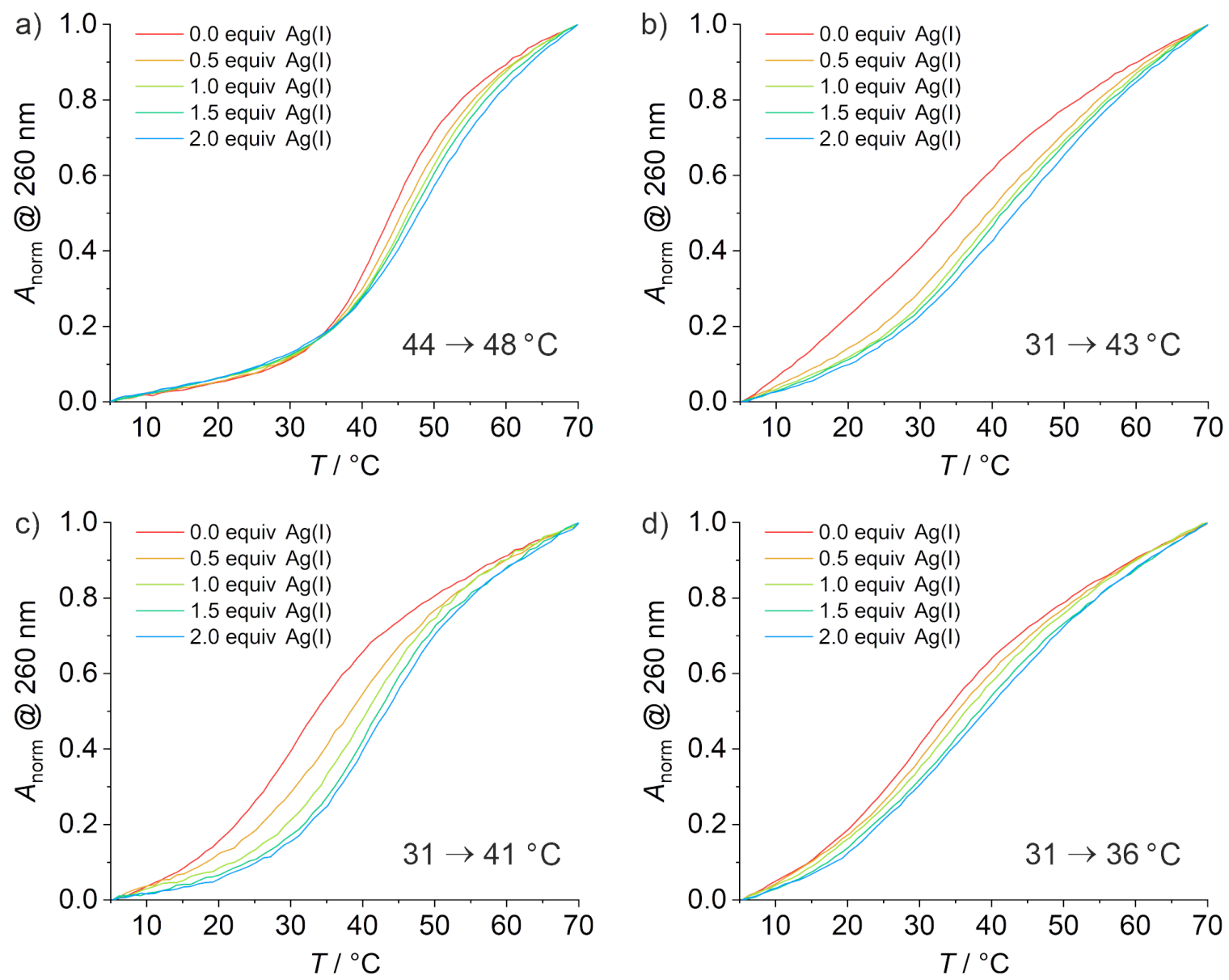

Figure 3: Temperature-dependent normalized UV absorbance at $260 \mathrm{~nm}$ for oligonucleotides a) 1af, b) 1bf, c) 1cf, and d) 1df in the absence (red line) and presence of increasing amounts of $\mathrm{Ag}(\mathrm{I})$. The melting temperatures in the presence of 0.0 and 1.0 equiv of $\mathrm{Ag}(\mathrm{I})$ are given, too. Conditions: $1 \mu \mathrm{M}$ oligonucleotide, $50 \mathrm{mM} \mathrm{NaClO}_{4}, 5 \mathrm{mM}$ MOPS buffer ( $\mathrm{pH} \mathrm{6.8)}$. 
positive Cotton effect between 260 and $290 \mathrm{~nm}$ as well as a negative Cotton effect between 220 and $260 \mathrm{~nm}$, indicating a B-type DNA structure [39]. For the most part, significant changes or trends cannot be observed in the CD spectra, indicating that the formation of the $\mathrm{Ag}(\mathrm{I})$-mediated base pairs as deduced from the melting curves does not influence the overall DNA topology. This is a well-known feature of the $\mathrm{Im}-\mathrm{Ag}(\mathrm{I})-\mathrm{Im}$ base pair [31].

\section{Fluorescence spectroscopy assay}

In 2003, the ATP/AMP-binding aptamer was applied in combination with a fluorophore (fluorescein), a quencher (DABCYL), and complementary oligonucleotides to devise a system referred to as structure-switching signaling aptamer [40]. Based on this concept, two systems were devised to investigate whether the Im-Ag(I)-Im base pairs could be applied to manipulate the formation of the aptamer:AMP complex. System A utilizes the 5'-fluorescein-labeled imidazole-containing oligonucleotide derived from the aptamer (1af, 1bf, 1cf, 1df) in combination with a complementary oligonucleotide (1q, quencherlabeled DNA) bearing a DABCYL moiety at the 3' terminus (Figure 4A and Figure 5). In the absence of AMP, the sequences should form a regular duplex structure, with the fluorescence of the fluorescein being quenched by the DABCYL moiety located nearby. In the presence of AMP and $\operatorname{Ag}(\mathrm{I})$, the aptamer should instead form the aptamer:AMP complex, releasing the quencher-labeled DNA and henceforth restoring the fluorescence. Ideally, if the aptamer is suitably modified with imidazole (Figure 4A), the aptamer:AMP complex should be too unstable to form in the absence of $\mathrm{Ag}(\mathrm{I})$. In this case, the system should only fluoresce when both AMP and $\mathrm{Ag}(\mathrm{I})$ are present. System B functions in a similar manner (Figure 4B), but instead of the aptamer carrying the fluorescent label, it utilizes two complementary sequences, one carrying fluorescein (2f) and the other carrying DABCYL (2q).

First, the change in fluorescence was investigated for all sequences of the system A via fluorescence spectroscopy. The



measurements were conducted at $\mathrm{pH} 7.4$ and 8.1. In both cases, similar results were obtained. Hence, the data for $\mathrm{pH} 7.4$ will be presented and discussed in the following (Figure 6), whereas the data for $\mathrm{pH} 8.1$ can be found in Supporting Information File 1 (Figure S2). The fluorescence intensities were normalized according to $I_{\text {norm }}=F / F_{0}$, wherein $F=$ fluorescence intensity and $F_{0}=$ fluorescence intensity of the fluorescein-labeled oligonucleotide without any additions. As expected, the oligonucleotide 1af shows the most efficient quenching upon the addition of 1q with a $90 \%$ decrease in emission. Upon the addition of AMP, the emission increases again almost sevenfold, indicating a dissociation of the quencher-labeled oligonucleotide and subsequent formation of the AMP-bound structure. Adding 1 equiv of $\operatorname{Ag}(\mathrm{I})$ leads to no significant further change, as was expected for the imidazole-free derivative 1af. Nevertheless, the addition of 10 equiv of $\mathrm{Ag}(\mathrm{I})$ leads to a slight decrease in the emission. The oligonucleotides $\mathbf{1 b f}, \mathbf{1 c f}$, and $\mathbf{1 d f}$ all show less efficient quenching upon the addition of $\mathbf{1 q}$, which can be attri-

$$
1 a f+1 q
$$

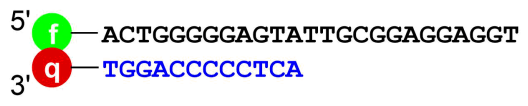

$$
1 c f+1 q
$$

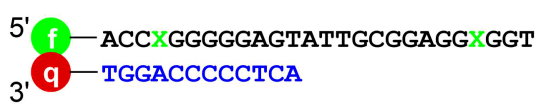

$1 b f+1 q$

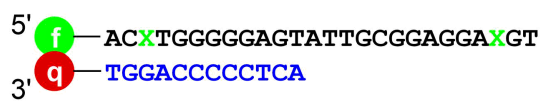

$1 d f+1 q$

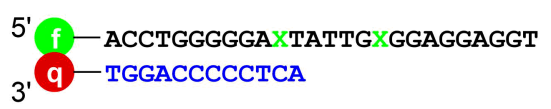

Figure 5: System A: the aptamers 1 af, $\mathbf{1 b f}, \mathbf{1 c f}$, and $\mathbf{1 d f}$ with the complementary sequence $\mathbf{1 q}(X=$ imidazole, $f=$ fluorescein, $q=D A B C Y L)$. 

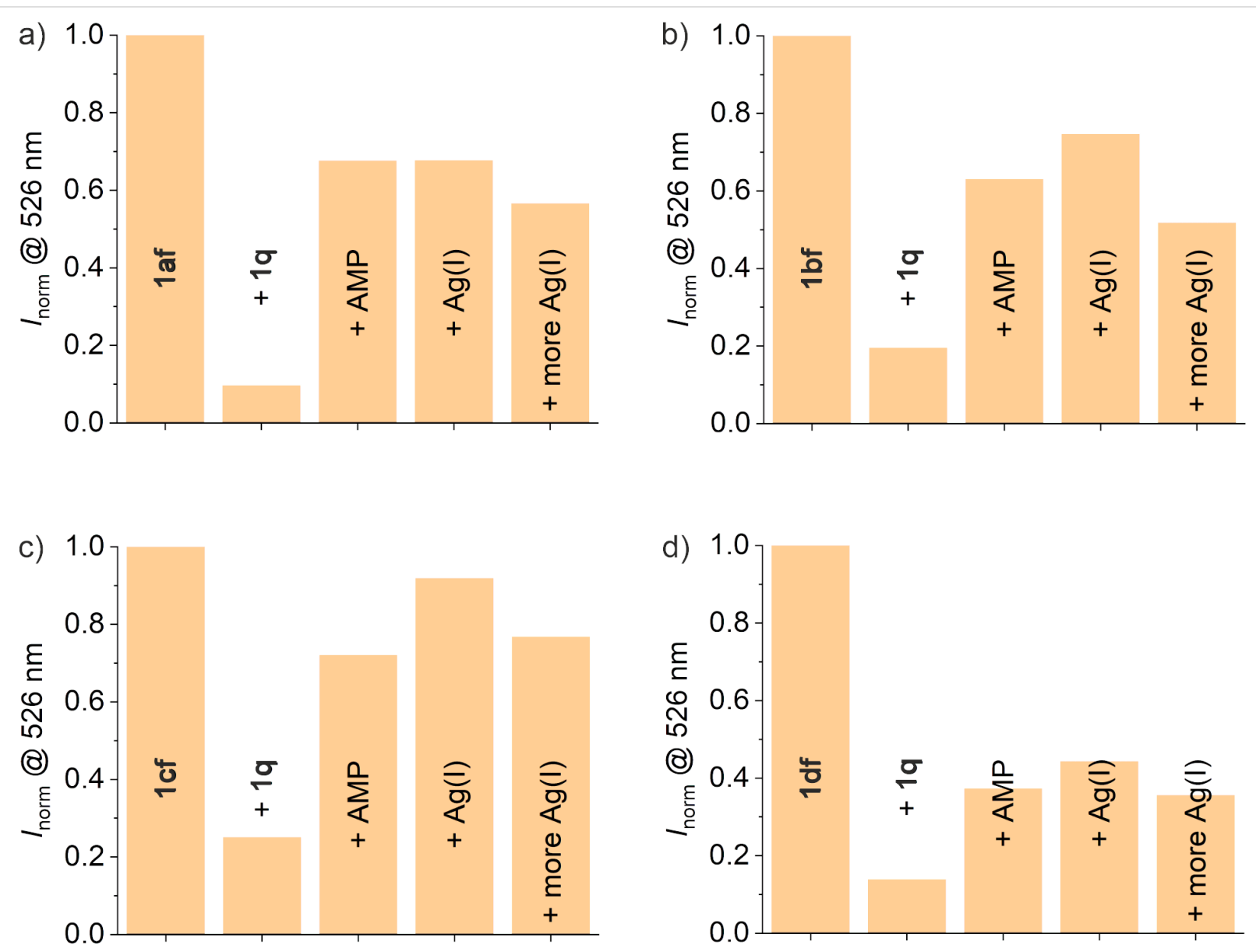

Figure 6: Normalized fluorescence intensity at $526 \mathrm{~nm}\left(\lambda_{\text {exc }}=490 \mathrm{~nm}\right)$ of a) 1af, b) 1bf, c) 1cf, and d) 1df prior to and after the successive addition of 1q, $1 \mathrm{mM}$ AMP, 1 equiv of $\mathrm{Ag}(\mathrm{I})$, and 9 more equiv of $\mathrm{Ag}(\mathrm{I})$, respectively. After each addition and before the respective measurement, the solution was heated to $40{ }^{\circ} \mathrm{C}$ for $10 \mathrm{~min}$ and then kept at $22^{\circ} \mathrm{C}$ for $30 \mathrm{~min}$ (conditions: $40 \mathrm{nM}$ fluorophore-labeled DNA, $80 \mathrm{nM} \mathrm{1q,} 300 \mathrm{mM} \mathrm{NaClO}, 5 \mathrm{mM}$ $\mathrm{Mg}\left(\mathrm{ClO}_{4}\right)_{2}$, and $20 \mathrm{mM}$ MOPS buffer $\left.(\mathrm{pH} 7.4)\right)$.

buted to the presence of the destabilizing mismatches involving imidazole. This effect is least pronounced for oligonucleotide 1df, which is quenched almost as effectively as 1af. All imidazole-containing aptamer derivatives show an increased emission upon the addition of AMP with an approximately threefold increase in the intensity. In contrast to aptamer 1af, however, they show a slight additional increase in emission upon the addition of 1 equiv of $\operatorname{Ag}(\mathrm{I})$. This effect is most pronounced for the derivative 1cf. Like 1af, the imidazole-containing aptamer derivatives show a decrease in intensity in the presence of excess $\mathrm{Ag}(\mathrm{I})$. This common observation implies that the first slight increase upon the addition of 1 equiv of $\mathrm{Ag}(\mathrm{I})$ may be attributed to the formation of an $\mathrm{Im}-\mathrm{Ag}(\mathrm{I})-\mathrm{Im}$ base pair. The decreased emission with excess of $\mathrm{Ag}(\mathrm{I})$ may then be caused by less specific interactions between the $\operatorname{Ag}(\mathrm{I})$ ions and DNA, as $\mathrm{Ag}(\mathrm{I})$ is known to also bind to natural nucleobases [41-43]. Again, this non-specific binding of excess $\mathrm{Ag}(\mathrm{I})$ can be deduced from the melting curves, as is exemplarily shown for the duplex formed from 1af and 1q (Figure S3a in Supporting Information
File 1). It is also notable that of all aptamer derivatives, $\mathbf{1 d f}$ shows the lowest fluorescence intensity in the presence of AMP, indicating an overall reduced affinity of $\mathbf{1 d f}$ to AMP.

It was further investigated whether the order of the addition of AMP and $\mathrm{Ag}(\mathrm{I})$ influences the outcome of the experiment, as it may be anticipated that free AMP competes for the binding of $\mathrm{Ag}(\mathrm{I})$. However, no significant changes in the level of emission after the addition of both $\mathrm{Ag}(\mathrm{I})$ and AMP were observed (see Supporting Information File 1, Figure S4).

A variant of system $\mathrm{A}$, in which the quencher oligonucleotide $\mathbf{1 q}$ is replaced by the slightly longer sequence $\mathbf{1 q 2}$, was investigated as well. The two additional bases of $1 \mathbf{1 q} 2$ should be able to form two more canonical base pairs with the aptamer and therefore compensate for the destabilization caused by the imidazole mismatches. As expected, all fluorophore-labeled aptamers show a more effective quenching upon the addition of $\mathbf{1 q 2}$ (Figure S5 in Supporting Information File 1). The relative 
changes in the emission are quite similar to the ones observed with 1q though.

Again, the measurements were repeated with $\mathrm{Ag}(\mathrm{I})$ being added prior to AMP. While adding 1 equiv of $\mathrm{Ag}(\mathrm{I})$ leads to only marginal changes in the emission, adding $\mathrm{Ag}(\mathrm{I})$ in excess leads to a significant increase in fluorescence intensity for all sequences (Figure S6 in Supporting Information File 1). As this change is not limited to the imidazole-containing aptamer derivatives, it is probably caused by non-specific interactions of the $\mathrm{Ag}(\mathrm{I})$ ions with the natural nucleobases. Interestingly, when the shorter quencher sequence 1q is used, excess $\operatorname{Ag}(\mathrm{I})$ leads to a decrease in the emission when AMP is present already. As to why $\mathbf{1 q} 2$ behaves differently is unclear. Furthermore, while the relative increase in the emission caused by $\mathrm{Ag}(\mathrm{I})$ is similar for all sequences, $\mathbf{1 c f}$ shows a much greater change when AMP is added. Possibly, 1cf possesses a higher affinity to AMP under these conditions than the other sequences.

In a second set of fluorescence experiments, system $B$ was investigated analogously. In the system $B$, the fluorescein moiety is not attached to the aptamer derivative but to the oligonucleotide $2 \mathbf{f}$ (Figure 7).

The fluorescence of $\mathbf{2} \mathbf{f}$ is defined as $100 \%$ in this set of experiments, as it was found that the presence of the aptamer derivatives significantly reduces the fluorescence. It should be reasonable to assume that the degree to which the emission is quenched upon the aptamer addition serves as a first indicator of the stability of the resulting duplex. As such, the addition of oligonucleotides 1a and $\mathbf{1 b}$, which do not form mismatched base pairs with the oligonucleotide $\mathbf{2 f}$, as well as $\mathbf{1 c}$, which only forms one mismatched pair at the 3' terminus of $\mathbf{2 f}$, results in a similar reduction in the fluorescence (Figure 8). The addition of oligonucleotide 1d, which forms one mismatched base pair with $2 \mathbf{f}$ close to the fluorescein moiety, leads to hardly any reduction in the fluorescence emission, indicating that $2 \mathbf{f}$ binds less effec- tively (if at all). The oligonucleotide $2 \mathbf{q}$ quenches the fluorescence of the duplexes formed by $\mathbf{2 f}$ and $\mathbf{1 a}, \mathbf{1 b}$ or $\mathbf{1 c}$ with similar effectiveness, while almost no quenching occurs with 1d This can be attributed to either $\mathbf{2 q}$ or $\mathbf{2 f}$ (or both) not binding effectively to 1d, which would be in line with the fact that in both cases one imidazole-containing mismatch would be present in the duplex. Except for the system involving the aptamer 1a, none of the systems shows a significant response to AMP in the absence of $\mathrm{Ag}(\mathrm{I})$. Unexpectedly, even after the addition of 1 equiv of $\operatorname{Ag}(\mathrm{I})$, the fluorescence emission does not significantly increase either. Adding an excess of $\mathrm{Ag}(\mathrm{I})$ does increase the emission in all cases. This effect hence could be caused by unspecific interactions between $\mathrm{Ag}(\mathrm{I})$ and the canonical nucleobases and cannot be attributed to the formation of $\operatorname{Im}-\mathrm{Ag}(\mathrm{I})-\mathrm{Im}$ base pairs. Interestingly, such proposed unspecific interactions do not lead to an increase in $T_{\mathrm{m}}$ for the duplexes formed from 1a, $\mathbf{2 f}$ and $\mathbf{2 q}$ (Figure S3b, Supporting Information File 1), which could possibly be due to the ternary nature of this duplex. It appears as if the presence of excess $\operatorname{Ag}(\mathrm{I})$ somehow disrupts the binding of $\mathbf{2 f}$ and $\mathbf{2 q}$ to the aptamer derivatives.

\section{Assay with immobilized ATP}

To finally evaluate whether the incorporation of Im:Im pairs into the aptamer allows for its target affinity to be manipulated, a binding assay using ATP-agarose gel was performed [44]. Towards this end, the aptamer derivatives 1 af-1df were loaded onto an agarose gel containing immobilized ATP, followed by washing with buffer. The elution was quantified by UV-vis spectroscopy.

In the absence of $\operatorname{Ag}(\mathrm{I})$, the aptamer derivatives bearing imidazole residues show a lower affinity to ATP than the unmodified aptamer (Figure 9). While only $17 \%$ of the DNA is eluted in the five washing fractions of 1af, the amount of eluted DNA is almost twice as high for $\mathbf{1 b f}$ with $32 \%$ being washed off the column. This effect is even more pronounced for the deriva-
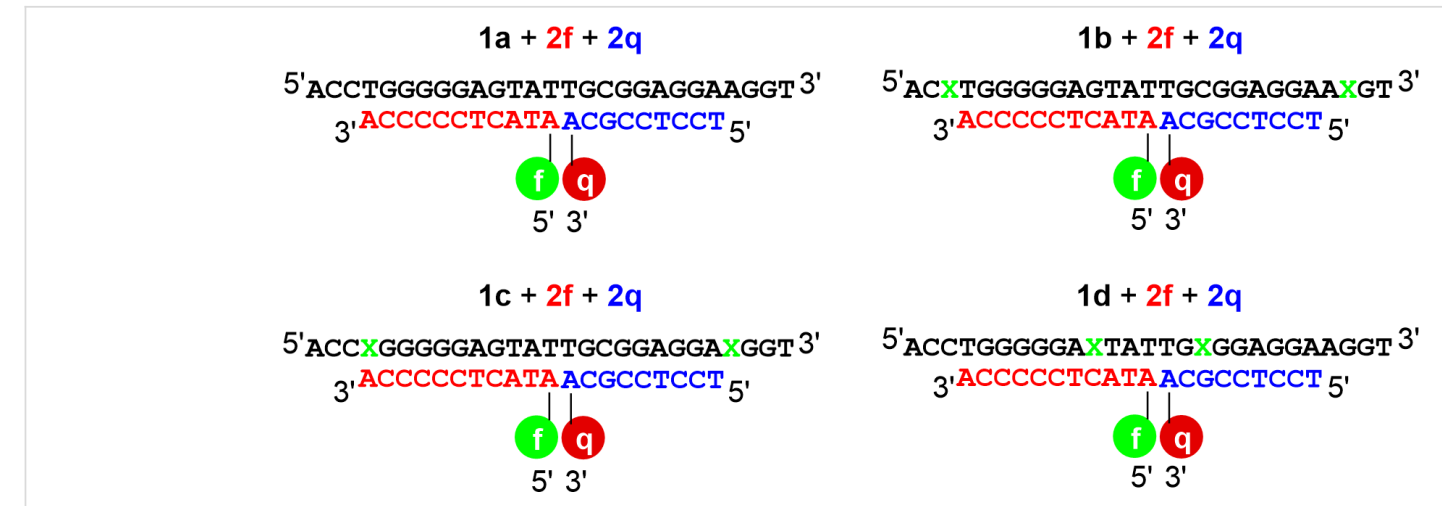

Figure 7: System B: aptamers $\mathbf{1 a}, \mathbf{1 b}, \mathbf{1 c}$, and $\mathbf{1 d}$ with the complementary oligonucleotides $\mathbf{2} \mathbf{f}$ and $\mathbf{2 q}(X=$ imidazole, $f=$ fluorescein, $q=D A B C Y L)$ 

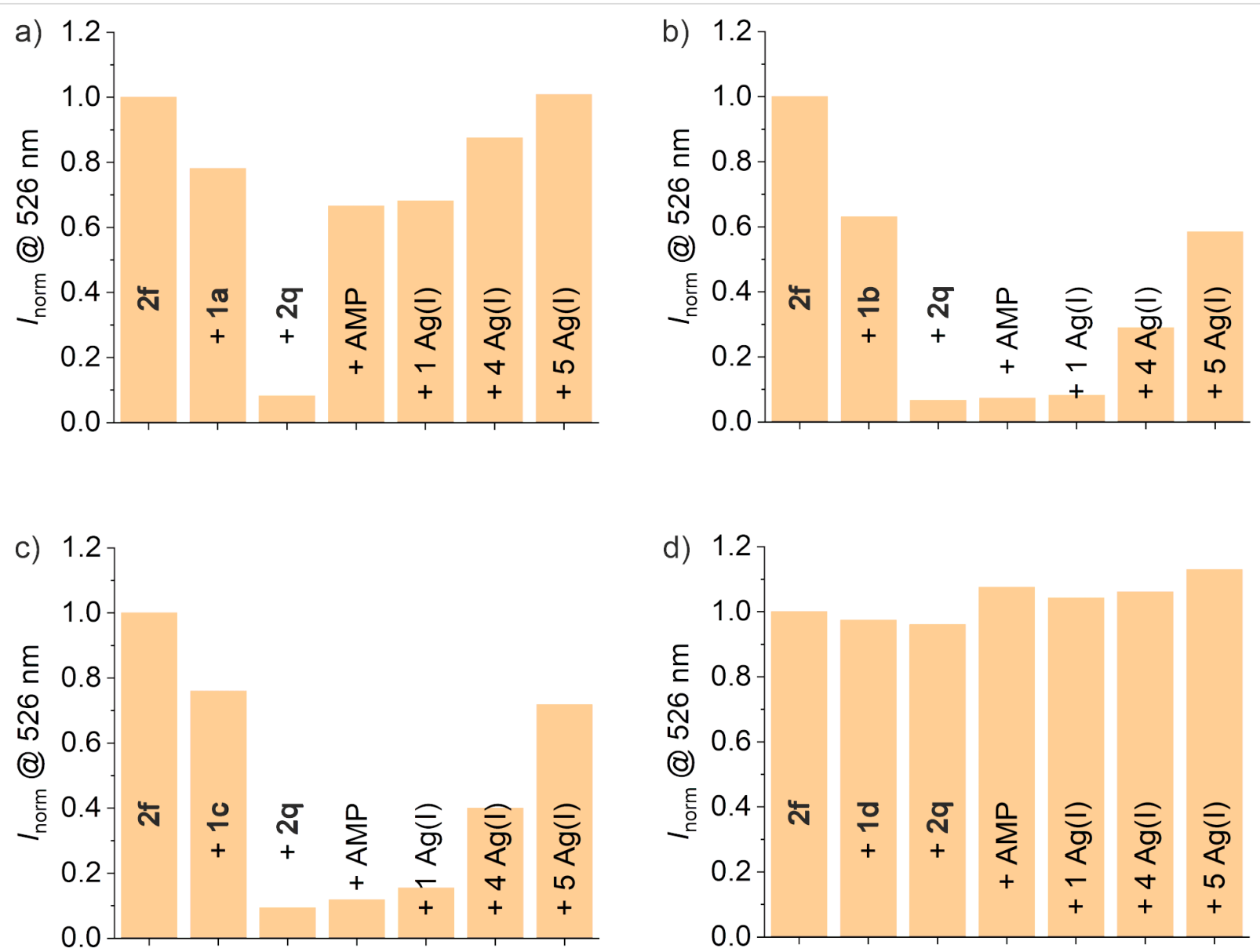

Figure 8: Normalized fluorescence intensity at $526 \mathrm{~nm}\left(\lambda_{\mathrm{exc}}=490 \mathrm{~nm}\right)$ of the oligonucleotide $2 \mathrm{f}$ before and after the successive addition of the aptamer (derivatives) a) 1a, b) $\mathbf{1 b}, \mathrm{c}$ ) $\mathbf{1 c}$, and d) 1d, of $\mathbf{2 q}$, of $1 \mathrm{mM} \mathrm{AMP}$, and of increasing equiv of $\mathrm{Ag}(\mathrm{I})$. After every addition and before the respective measurement, the solution was heated to $40{ }^{\circ} \mathrm{C}$ for $10 \mathrm{~min}$ and then kept at $22{ }^{\circ} \mathrm{C}$ for 30 min (conditions: $40 \mathrm{nM} 2 \mathrm{f}$; $80 \mathrm{nM}$ aptamer derivative; $120 \mathrm{nM} 2 \mathrm{q}, 300 \mathrm{mM} \mathrm{NaClO}_{4}, 5 \mathrm{mM} \mathrm{Mg}\left(\mathrm{ClO}_{4}\right)_{2}$, and $20 \mathrm{mM}$ MOPS buffer (pH 8.1)).

tives 1cf and 1df, which are almost completely eluted in the five washing fractions ( $87 \%$ and $95 \%$, respectively). As seen before in the fluorescence spectroscopy assay (vide supra), the presence of an Im:Im mismatch directly adjacent to the binding pocket of the aptamer significantly disrupts its ability to bind ATP. Locating the mismatch further away from the binding pocket has a much less pronounced impact. Particularly the G:C pair close to the loop region that has been replaced by an Im:Im mismatch in 1df seems to be important for the stability of the aptamer:ATP complex. As can be seen in the elution profiles, 1df is eluted fastest from the column (Figure 9).

Adding 1 equiv of $\operatorname{Ag}(\mathrm{I})$ to the aptamer solution prior to conducting the binding assay leads to significant changes in the affinity particularly of $\mathbf{1 e f}$ and $\mathbf{1 d f}$ to the immobilized ATP (Figure 10). With $35 \%$ of the aptamer being eluted during the five washing steps, $\mathbf{1 c f}$ now shows essentially the same ATP affinity as $\mathbf{1 b f}$. The affinity of $\mathbf{1 d f}$ remains the lowest of all aptamer derivatives. However, even with this derivative an

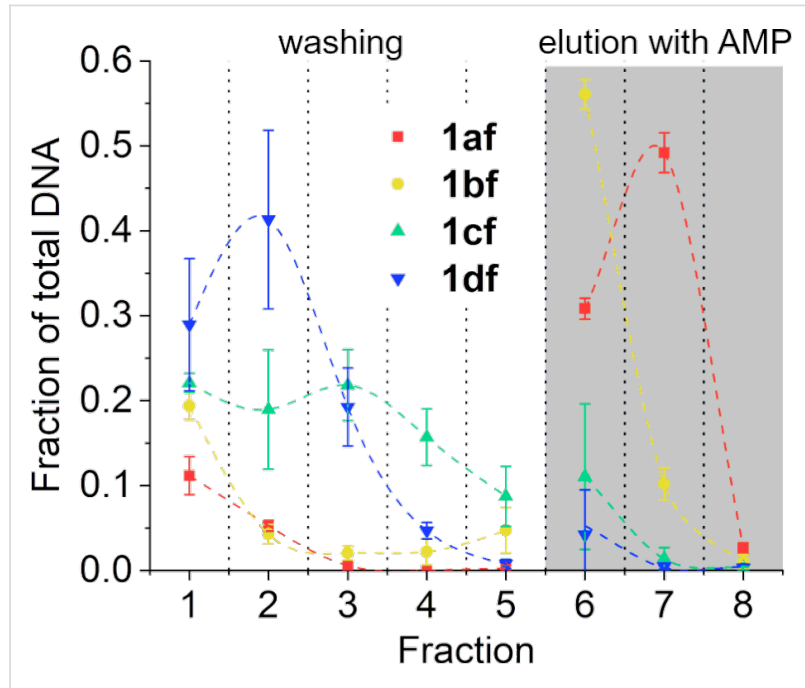

Figure 9: Elution of the aptamer derivatives from the ATP-agarose gel in the absence of $\mathrm{Ag}(\mathrm{I})$ : $\mathbf{1}$ af (red), $\mathbf{1} \mathbf{b f}$ (yellow), $\mathbf{1 c f}$ (green), and $\mathbf{1 d f}$ (blue) $(n=3)$. Conditions: $1 \mu \mathrm{M}$ oligonucleotide, $300 \mathrm{mM} \mathrm{NaClO}_{4}$, $5 \mathrm{mM} \mathrm{Mg}\left(\mathrm{ClO}_{4}\right)_{2}$, and $20 \mathrm{mM}$ MOPS buffer $(\mathrm{pH} 7.4)$. 
almost tenfold increase is found. It is noteworthy that the elution profiles of the modified aptamers after the addition of $\mathrm{Ag}(\mathrm{I})$ are very similar to the one of $\mathbf{1 a f}$ (Figure 10). The increased affinity of the derivatives can likely be attributed to the formation of stable $\mathrm{Im}-\mathrm{Ag}(\mathrm{I})-\mathrm{Im}$ base pairs, as the unmodified aptamer does not show an increase in affinity upon the addition of $\operatorname{Ag}(\mathrm{I})$. The position of the metal-mediated base pair seems to be of great importance, as the most significant increases in affinity are observed when the $\mathrm{Im}-\mathrm{Ag}(\mathrm{I})-\mathrm{Im}$ base pair is situated directly adjacent to the ATP binding pocket. When located in-between the Watson-Crick base pairs of the stem region, as in the case of $\mathbf{1 b f}$, no significant increase in the affinity is observed.

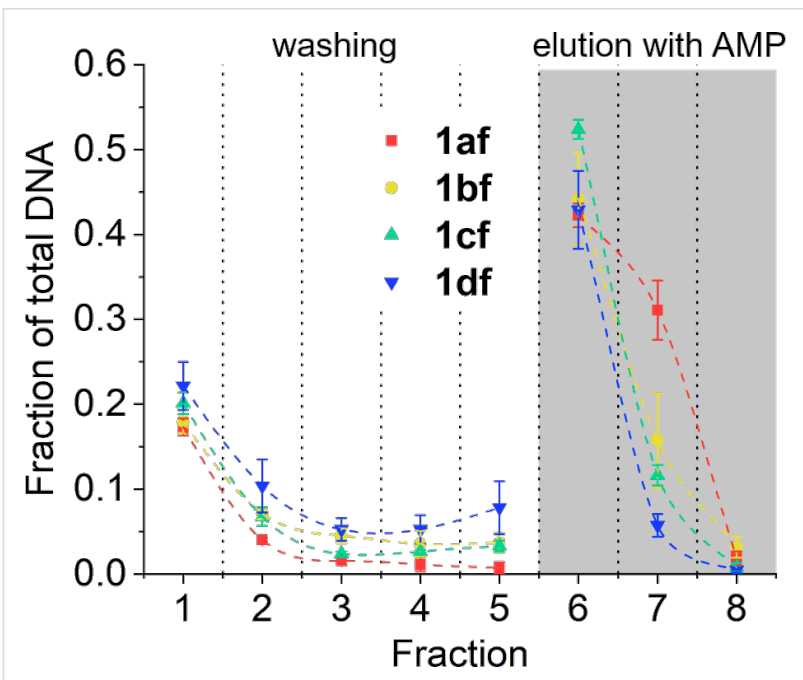

Figure 10: Elution of the aptamers from the ATP-agarose gel in the presence of 1 equiv of $\mathrm{Ag}(\mathrm{l})$ : 1 af (red), $\mathbf{1 b f}$ (yellow), $1 \mathrm{cf}$ (green), and 1 df (blue) $(n=3)$. Conditions: $1 \mu \mathrm{M}$ oligonucleotide, $300 \mathrm{mM} \mathrm{NaClO}_{4}$, $5 \mathrm{mM} \mathrm{Mg}\left(\mathrm{ClO}_{4}\right)_{2}$, and $20 \mathrm{mM}$ MOPS buffer ( $\mathrm{pH} \mathrm{7.4)}$.

To evaluate whether the aptamers are still specific when modified with the imidazole moiety, their affinity for GMP (guanosine monophosphate) was probed, too. As expected, the unmodified aptamer 1af cannot be eluted from the ATP affinity column by means of a GMP solution (see Supporting Information File 1, Figure S7a). Similarly, the aptamer derivatives 1bf, 1cf, and 1df are not eluted by GMP either (see Supporting Information File 1, Figure S7b). This strongly suggests that the modified aptamers are still specific.

The binding assays were repeated using the respective aptamers lacking the fluorescein label $(\mathbf{1 a}, \mathbf{1 b}, \mathbf{1 c}$, and 1d; Figure S8 in Supporting Information File 1). Without the fluorescent marker, a quantification of the eluted oligonucleotide has to be performed by using UV spectroscopy. Hence, only the amount of DNA eluted during the initial five washing steps can be quantified. It is impossible to determine the amount of the oligo- nucleotide eluted by the AMP solution, as AMP absorbs in the same wavelength range as DNA. It is, however, possible to compare the elution profiles during the washing phase. Interestingly, the data for aptamer $\mathbf{1 b}$ differ somewhat from those of the fluorescein-labeled oligonucleotide $\mathbf{1 b f}$. For example, in the absence of $\operatorname{Ag}(\mathrm{I}), \mathbf{1 b}$ shows a far lower ATP affinity than $\mathbf{1 b f}$ with almost the entire DNA being eluted during the washing steps. On the other hand, the aptamers 1c and 1d show comparable elution profiles, as do the derivatives $1 \mathbf{c f}$ and $\mathbf{1 d f}$. In the presence of 1 equiv of $\operatorname{Ag}(\mathrm{I})$, the assays indicate a restored affinity towards ATP for 1c and 1d, similar to that of aptamer 1a without imidazole moieties. Surprisingly, the affinity of $\mathbf{1 b}$ remains almost unchanged.

Overall, it seems that the fluorescein label influences the affinity of the aptamers to ATP only in the case of $\mathbf{1 b} / \mathbf{1 b f}$ where the imidazole moiety is located closest to the fluorophore.

\section{Conclusion}

The metal-mediated $\mathrm{Im}-\mathrm{Ag}(\mathrm{I})-\mathrm{Im}$ base pair can be used to modulate the affinity of the ATP-binding aptamer to its target. Placing an Im:Im mispair close to the ATP binding pocket significantly reduces the aptamer affinity, whereas a localization closer to the end of the duplex, where fraying is possible, has less of an influence. Importantly, the addition of $\mathrm{Ag}(\mathrm{I})$, which is incorporated into the Im:Im mispair to form a stabilizing $\mathrm{Im}-\mathrm{Ag}(\mathrm{I})$-Im pair, largely restores the ability of the aptamer derivative to bind to its target. The ability to modulate the aptamer affinity by adding suitable transition metal ions extends the applicability of aptamers even further, as it allows triggering the function at any desired point. Further optimizations will be necessary to eliminate the effect of excess transition metal ions and to enable a more complete switching of the aptamer function. This could be possible by using other metal-mediated base pairs, based either on other metal ions or on other artificial nucleobases.

\section{Experimental}

The reagents were purchased from Acros Organics, ABCR, Sigma-Aldrich, Activate Scientific, and Alfa Aesar and were used without further purification. The solvents used were purchased from VWR, Sigma-Aldrich, ABCR, Fluka, Fisher Scientific, and Merck. Dry pyridine was purchased from Acros Organics. Dichloromethane was distilled and dried over molecular sieves. Milli-Q water was used to prepare solutions and buffers. The silica gel used for product purification (Geduran ${ }^{\circledR}$ Si60, 40-63 $\mu \mathrm{m}$ ) was purchased from Merck.

The DMT- and phosphoramidite-protected imidazole nucleoside as required for automated DNA solid-phase synthesis was synthesized as previously reported [30]. The oligonucleotides 
were synthesized on a DNA/RNA synthesizer H-8 (K\&A Laborgeräte) using standard protocols for automated solidphase synthesis (coupling time: $1000 \mathrm{~s}$ for unnatural nucleosides). All natural nucleosides (A, T, G, and C), the fluorescein phosphoramidite as well as the DABCYL-CPGs were obtained from Glen Research. The oligonucleotides were deprotected and cleaved from the support by incubation in AMA solution (1:1, $40 \%$ methylamine and aqueous ammonia) at $65^{\circ} \mathrm{C}$ for $15 \mathrm{~min}$. They were purified using denaturing polyacrylamide gel electrophoresis (gel solution: $7 \mathrm{M}$ urea, $1 \mathrm{TBE}$ buffer, 14 or $18 \%$ (depending on the length of the oligonucleotide) polyacrylamide/bisacrylamide (29:1); loading buffer: $11.8 \mathrm{M}$ urea, $42 \mathrm{mM}$ Tris $\cdot \mathrm{HCl}$ ( $\mathrm{pH} 7.5$ ), 0.83 mM EDTA ( $\mathrm{pH} 8.0$ ), 8\% sucrose), and desalted using NAP 10 columns. MALDI-TOF spectrometry was used to characterize the oligonucleotides either in a 3-hydroxypicolinic acid (3-HPA)/ammonium acetate matrix or in a 3-HPA in TA50 solvent matrix (50:50, v/v acetonitrile $/ 0.1 \%$ TFA in water) containing $10 \mathrm{mg} / \mathrm{mL}$ diammonium hydrogen citrate (Supporting Information File 1, Table S1, Figures S9-S20). The purity was confirmed by means of HPLC chromatography (Figures S21-S32, Supporting Information File 1). Towards this end, a Macherey-Nagel NUCLEODUR C18 HTec column $(5 \mu \mathrm{m}, 124 \times 4 \mathrm{~mm})$ was used in combination with the following eluents at a flow rate of $1 \mathrm{~mL} / \mathrm{min}$ : trimethylamine/acetic acid 1:1, $10 \mathrm{mM}$ in water (solvent $\mathrm{A}$ ) and trimethylamine/acetic acid $1: 1,10 \mathrm{mM}$ in water/ $\mathrm{CH}_{3} \mathrm{CN}$ 1:4 (solvent B). Gradient applied: 0-5 min, 3\% B; 5-45 min, $3-40 \%$ B; $45-50 \mathrm{~min}, 100 \% \mathrm{~B}$. The quantification of the sequences was achieved using a Thermo Scientific NanoDrop 2000c photospectrometer. The molar extinction coefficients of the oligonucleotides were calculated from the known $\varepsilon_{260}$ values of the natural nucleobases as well as fluorescein and DABCYL. An $\varepsilon_{260}$ of 0.0 was used for the imidazole deoxyribonucleoside.

The binding assays were conducted using an ATP-loaded agarose gel obtained from Sigma-Aldrich (cross-linked 4\% beaded agarose, ATP is attached at its $\mathrm{C} 8$ position via a $9 \mathrm{C}$ linker, 1-5 $\mu \mathrm{mol}$ ATP per $\mathrm{mL}$ gel). For the binding assay, $5 \mathrm{nmol}$ DNA in $200 \mu \mathrm{L}$ column buffer $\left(300 \mathrm{mM} \mathrm{NaClO}_{4}, 5 \mathrm{mM}\right.$ $\mathrm{Mg}\left(\mathrm{ClO}_{4}\right)_{2}, 20 \mathrm{mM}$ MOPS (pH 7.4)) were loaded onto $500 \mu \mathrm{L}$ of agarose gel pre-equilibrated in column buffer. After $5 \mathrm{~min}$, the column was washed five times with column buffer $(1 \mathrm{~mL})$ and then eluted three times with $3 \mathrm{mM}$ AMP (or GMP) solution in column buffer $(750 \mu \mathrm{L}$ each). Each fraction was collected individually, lyophilized, and the residue dissolved in $1 \mathrm{~mL}$ water. The DNA was quantified using the NanoDrop 2000c and the calculated $\varepsilon_{260}$ values of the oligonucleotides as well as the $\varepsilon_{490}$ value of fluorescein. When conducting the binding assays in the presence of $\mathrm{Ag}(\mathrm{I}), 1$ equivalent of $\mathrm{AgClO}_{4}$ was added to $5 \mathrm{nmol}$ DNA in $200 \mu \mathrm{L}$ column buffer and the solution was left at room temperature for $15 \mathrm{~min}$ before applying it to the column. The assay was performed in triplicate.

Fluorescence spectra were recorded on a Chirascan V100 with CCD fluorometer instrument with excitation at $490 \mathrm{~nm}$, an emission range of 200-995 nm, and a data interval of $0.8 \mathrm{~nm}$. First, the fluorescence intensity of the fluorescein-labeled DNA was measured at $40 \mathrm{nM}$ in buffer $\left(300 \mathrm{mM} \mathrm{NaClO}_{4}, 5 \mathrm{mM}\right.$ $\mathrm{Mg}\left(\mathrm{ClO}_{4}\right)_{2}, 20 \mathrm{mM}$ MOPS (pH 8.1)) at $22{ }^{\circ} \mathrm{C}$. After adding the quencher-labeled DNA, AMP, or $\operatorname{Ag}(\mathrm{I})$, the solution was heated to $40{ }^{\circ} \mathrm{C}$ for $10 \mathrm{~min}$ and then kept at $22{ }^{\circ} \mathrm{C}$ for $30 \mathrm{~min}$ before recording the fluorescence intensity again.

\section{Supporting Information}

\section{Supporting Information File 1}

Results of additional fluorescence spectroscopy assays, CD spectra, additional melting curves, results of additional assays with immobilized ATP, oligonucleotide sequences, MALDI-TOF spectra of the oligonucleotides and HPLC traces to confirm the oligonucleotide purity.

[https://www.beilstein-journals.org/bjoc/content/ supplementary/1860-5397-16-236-S1.pdf]

\section{Acknowledgements}

We thank D. Defayay for performing the HPLC analysis of the oligonucleotides.

\section{ORCID ${ }^{\circledR}$ iDs}

Marius H. Heddinga - https://orcid.org/0000-0001-9450-6579 Jens Müller - https://orcid.org/0000-0003-4713-0606

\section{References}

1. Famulok, M.; Hartig, J. S.; Mayer, G. Chem. Rev. 2007, 107, 3715-3743. doi:10.1021/cr0306743

2. Hermann, T.; Patel, D. J. Science 2000, 287, 820-825. doi:10.1126/science.287.5454.820

3. Wilson, D. S.; Szostak, J. W. Annu. Rev. Biochem. 1999, 68, 611-647. doi:10.1146/annurev.biochem.68.1.611

4. Keefe, A. D.; Pai, S.; Ellington, A. Nat. Rev. Drug Discovery 2010, 9, 537-550. doi:10.1038/nrd3141

5. Liu, J.; Cao, Z.; Lu, Y. Chem. Rev. 2009, 109, 1948-1998. doi:10.1021/cr030183i

6. Tombelli, S.; Minunni, M.; Mascini, M. Biosens. Bioelectron. 2005, 20, 2424-2434. doi:10.1016/j.bios.2004.11.006

7. Willner, I.; Zayats, M. Angew. Chem., Int. Ed. 2007, 46, 6408-6418. doi:10.1002/anie.200604524

8. Wang, S.; Yue, L.; Li, Z.-Y.; Zhang, J.; Tian, H.; Willner, I. Angew. Chem., Int. Ed. 2018, 57, 8105-8109. doi:10.1002/anie.201803371 
9. Shin, J.-S.; Pierce, N. A. J. Am. Chem. Soc. 2004, 126, 10834-10835. doi:10.1021/ja047543j

10. Del Grosso, E.; Ragazzon, G.; Prins, L. J.; Ricci, F. Angew. Chem., Int. Ed. 2019, 58, 5582-5586. doi:10.1002/anie.201812885

11. Punt, P. M.; Clever, G. H. Chem. Sci. 2019, 10, 2513-2518. doi:10.1039/c8sc05020a

12. Lake, R. J.; Yang, Z.; Zhang, J.; Lu, Y. Acc. Chem. Res. 2019, 52, 3275-3286. doi:10.1021/acs.accounts.9b00419

13. Naskar, S.; Guha, R.; Müller, J. Angew. Chem., Int. Ed. 2020, 59, 1397-1406. doi:10.1002/anie.201905913

14. Takezawa, Y.; Müller, J.; Shionoya, M. Chem. Lett. 2017, 46, 622-633. doi:10.1246/cl.160985

15. Müller, J. Coord. Chem. Rev. 2019, 393, 37-47. doi:10.1016/j.ccr.2019.05.007

16. Santamaría-Díaz, N.; Méndez-Arriaga, J. M.; Salas, J. M.; Galindo, M. A. Angew. Chem., Int. Ed. 2016, 55, 6170-6174. doi:10.1002/anie.201600924

17. Jash, B.; Müller, J. Chem. - Eur. J. 2017, 23, 17166-17178. doi:10.1002/chem.201703518

18. Ukale, D. U.; Lönnberg, T. Angew. Chem., Int. Ed. 2018, 57, 16171-16175. doi:10.1002/anie.201809398

19. Takezawa, Y.; Yoneda, S.; Duprey, J.-L. H. A.; Nakama, T.; Shionoya, M. Chem. Sci. 2016, 7, 3006-3010. doi:10.1039/c6sc00383d

20. Takezawa, Y.; Nakama, T.; Shionoya, M. J. Am. Chem. Soc. 2019, 141, 19342-19350. doi:10.1021/jacs.9b08955

21. Nakama, T.; Takezawa, Y.; Sasaki, D.; Shionoya, M. J. Am. Chem. Soc. 2020, 142, 10153-10162. doi:10.1021/jacs.0c03129

22. Engelhard, D. M.; Nowack, J.; Clever, G. H. Angew. Chem., Int. Ed. 2017, 56, 11640-11644. doi:10.1002/anie.201705724

23. Saran, R.; Kleinke, K.; Zhou, W.; Yu, T.; Liu, J. Biochemistry 2017, 56, 1955-1962. doi:10.1021/acs.biochem.6b01131

24. Saran, R.; Yao, L.; Hoang, P.; Liu, J. Biochimie 2018, 145, 145-150. doi:10.1016/j.biochi.2017.07.001

25. Huizenga, D. E.; Szostak, J. W. Biochemistry 1995, 34, 656-665. doi:10.1021/bi00002a033

26. Lin, C. H.; Patel, D. J. Chem. Biol. 1997, 4, 817-832. doi:10.1016/s1074-5521(97)90115-0

27. Wu, N.; Willner, I. Nanoscale 2017, 9, 1416-1422. doi:10.1039/c6nr08209b

28. Yang, J.; Jiang, S.; Liu, X.; Pan, L.; Zhang, C. ACS Appl. Mater. Interfaces 2016, 8, 34054-34060. doi:10.1021/acsami.6b10266

29. Walter, H.-K.; Bauer, J.; Steinmeyer, J.; Kuzuya, A.; Niemeyer, C. M.; Wagenknecht, H.-A. Nano Lett. 2017, 17, 2467-2472. doi:10.1021/acs.nanolett.7b00159

30. Johannsen, S.; Megger, N.; Böhme, D.; Sigel, R. K. O.; Müller, J. Nat. Chem. 2010, 2, 229-234. doi:10.1038/nchem.512

31. Petrovec, K.; Ravoo, B. J.; Müller, J. Chem. Commun. 2012, 48, 11844-11846. doi:10.1039/c2cc36169h

32. Tan, X.; Litau, S.; Zhang, X.; Müller, J. Langmuir 2015, 31 , 11305-11310. doi:10.1021/acs.langmuir.5b03183

33. Hensel, S.; Megger, N.; Schweizer, K.; Müller, J. Beilstein J. Org. Chem. 2014, 10, 2139-2144. doi:10.3762/bjoc.10.221

34. Léon, J. C.; She, Z.; Kamal, A.; Shamsi, M. H.; Müller, J.; Kraatz, H.-B. Angew. Chem., Int. Ed. 2017, 56, 6098-6102. doi:10.1002/anie.201700248
35. Léon, J. C.; González-Abradelo, D.; Strassert, C. A.; Müller, J. Chem. - Eur. J. 2018, 24, 8320-8324. doi:10.1002/chem.201801858

36. Naskar, S.; Hebenbrock, M.; Müller, J. Inorg. Chim. Acta 2020, 512, 119856. doi:10.1016/j.ica.2020.119856

37. Verma, S.; Mishra, A. K.; Kumar, J. Acc. Chem. Res. 2010, 43, 79-91. doi:10.1021/ar9001334

38. Huard, D. J. E.; Demissie, A.; Kim, D.; Lewis, D.; Dickson, R. M.; Petty, J. T.; Lieberman, R. L. J. Am. Chem. Soc. 2019, 141, 11465-11470. doi:10.1021/jacs.8b12203

39. Vorlíčková, M.; Kejnovská, I.; Bednářová, K.; Renčiuk, D.; Kypr, J. Chirality 2012, 24, 691-698. doi:10.1002/chir.22064

40. Nutiu, R.; Li, Y. J. Am. Chem. Soc. 2003, 125, 4771-4778. doi:10.1021/ja028962o

41. Kondo, J.; Tada, Y.; Dairaku, T.; Hattori, Y.; Saneyoshi, H.; Ono, A.; Tanaka, Y. Nat. Chem. 2017, 9, 956-960. doi:10.1038/nchem.2808

42. Zhao, H.; Leonard, P.; Guo, X.; Yang, H.; Seela, F. Chem. - Eur. J. 2017, 23, 5529-5540. doi:10.1002/chem.201605982

43. Funai, T.; Miyazaki, Y.; Aotani, M.; Yamaguchi, E.; Nakagawa, O.; Wada, S.-i.; Torigoe, H.; Ono, A.; Urata, H. Angew. Chem., Int. Ed. 2012, 51, 6464-6466. doi:10.1002/anie.201109191

44. Sassanfar, M.; Szostak, J. W. Nature 1993, 364, 550-553. doi:10.1038/364550a0

\section{License and Terms}

This is an Open Access article under the terms of the Creative Commons Attribution License (https://creativecommons.org/licenses/by/4.0). Please note that the reuse, redistribution and reproduction in particular requires that the authors and source are credited.

The license is subject to the Beilstein Journal of Organic Chemistry terms and conditions: (https://www.beilstein-journals.org/bjoc)

The definitive version of this article is the electronic one which can be found at: https://doi.org/10.3762/bjoc.16.236 